\title{
Palabra, Tiempo y Concepto en el pensamiento de Hegel
}

\author{
MANUEL JIMÉNEZ REDONDO \\ Universidad de Valencia
}

\section{Cuatro puntos de vista desde los que entender a Hegel}

Yo HE DICHO EN OTRA PARTE ${ }^{1}$ que a Hegel no se lo entiende bien si no se lo mira desde cuatro sitios distintos. El primero es Grecia. A Hegel hay que mirarlo desde Platón y Aristóteles, entendiendo que para Hegel es Aristóteles quien contiene lo más especulativo de Platón. Aristóteles convierte en elementos especulativamente articulados lo que en Platón se queda en elementos sueltos, abstractos ${ }^{2}$. La idea más básica que Hegel toma del Platón de El sofista es la de heterotes, la de que nada es sin ser lo otro de sí mismo e incluso lo absolutamente otro de sí mismo; en el más allá de sí no estar referido sino a sí mismo es para Hegel la idea de energeia de Aristóteles ${ }^{3}$.

El segundo sitio desde el que hay que mirar a Hegel es el Cristianismo. Es básica en todo el pensamiento de Hegel la noción cristiana de la autokenosis de lo absoluto, del autovaciamiento de lo absoluto. El absoluto no es lo que es sino haciéndose lo otro de sí. Dios se hace hombre. Y aquellos conceptos griegos, los conceptos de E'l sofista o del Filebo o del Parménides de Platón, los conceptos en general del Platón de "los cardos y espinas", 4 que aun en Grecia resultan enigmáticos, cobran una peculiar claridad cuando se entienden como conceptos de la representación cristiana de la autokenosis de lo absoluto.

El tercer elemento que hay tener en cuenta para entender a Hegel es el más irritante y el más desafiante por parte de Hegel. Lo podemos formular así: la representación cristiana traída a conceptos griegos, eso es la conciencia moderna

1 ALONSO MARTOS, Andrés, JIMÉNEZ REDONDO, Manuel (eds.), Figuraciones contemporáneas de lo absoluto, 200 años de la Fenomenología del espíritu de Hegel, Valencia: Universidad de Valencia, 2009, págs. 233 ss.

2 Cfr. HEGEL, G.W. F. , G.W.F. Hegel, Werke 18, Vorlesungen über die Geschichte der Philosophie, 1, Frankfurt: Suhrkamp, 1986, págs. 62 ss.

3 Ibid., págs. 132 ss.

4 lbid.,, págs. 61 ss. 
cuando conceptualmente se da alcance a sí misma. En Kant esa conciencia se tiene por primera vez delante con toda claridad a sí misma, pero sin hacerse pleno concepto de sí. El concepto griego de la representación cristiana es la razón kantiana, la razón ilustrada moderna, cuando, mirándose tal como queda en Kant, se hace adecuado concepto de sí. Y eso es Hegel. El tercer sitio, por tanto, el principal de ellos, desde el que hay que mirar a Hegel, es la obra de Kant. Todo lo que Hegel toma de los demás sitios, está, por así decirlo, al servicio de su lectura o relectura de la obra de Kant, y es en ello en lo que la obra de Hegel consiste. A Hegel no hay más remedio que mirarlo desde Grecia y desde el Cristianismo, precisamente por la radicalidad de su referencia a Kant. Hegel busca hacerse concepto de aquello que ocurre en Kant, que Kant deja sin conceptuar, pese a quedar en él a la vista. En cierto sentido, Hegel, ateniéndose a la letra de Kant, se comporta respecto a Kant de modo similar a como Pierre Menard se comporta respecto al texto de Cervantes en el cuento de Borges ${ }^{5}$.

Hegel toma el yo pienso de la analítica trascendental de la Crítica de la razón pura, el yo pienso que ha de acompañar todas mis representaciones, por detrás del cual no puede haber ya nada sino el yo pienso que ha de sostener toda representación incluso reflexiva de sí. Y Hegel toma asimismo el final de la dialéctica de la Crítica de la razón pura, toma las consideraciones con las que Kant cicrra la discusión y rechazo de los tres tipos de pruebas de la existencia de Dios: del argumento ontológico, del argumento cosmológico y del argumento del orden. Me voy a detener un poco en esto.

El argumento del orden, que Kant llama argumento físico-teológico $0^{6}$, postula una inteligencia ordenadora, pues ese orden no tiene su razón de ser en sí mismo, ya que podría también no haber sido. Ese argumento nos remite, por tanto, a otro, que tiene por motivo central la relación contingencia-necesidad. Kant lo llama argumento cosmológico. El argumento cosmológico dice que, si hay algo contingente, también ha de haber algo necesario; ahora bien, existo al menos yo -dice Kant-; por tanto existe un ser absolutamente necesario; se está suponiendo, aquí, pues, según parece, la completa contingencia del yo pienso ${ }^{7}$.

Pero este argumento cosmológico, si quiere evitar un regreso infinito, tiene que apoyarse en un argumento distinto, en un argumento que muestre que hay un ente necesario por su propio concepto. Y este ente necesario por su propio concepto es, conforme al argumento ontológico, la suma de toda realidad concebible, pensada in individuo o como individuo, es decir, aquel ente más grande que el cual nada puede ya concebirse, que por su concepto no puede menos de

5 BORGES, José Luis, "Pierre Menard, autor del Quijote", en: Ficciones" (1944)

6 KANT, $K r V$, A 620 ss.

7 KANT, $K r V, A 604 \mathrm{~s}$. 
existir, pues si no existiese no sería el ente más grande que el cual nada puede ya concebirse, pues cabría concebir otro mayor que él, a saber: el que siendo aquello más grande que lo cual nada puede ya concebirse, además existiese. La crítica que hace Kant de este argumento anticipa la idea desarrollada en concreto por Frege y Russell de que la existencia no es un predicado. Cuando decimos que los unicornios existen, no estamos añadiendo al concepto de unicornio ningún ingrediente más, del que ese concepto carecería si no hubiera unicornios, al igual que al concepto que tengo de cien taleros no le añade nada el que haya monedas o un conjunto de monedas que puedan caer bajo esa denominación, sino que estamos diciendo que hay entes en el mundo que son unicornios, sin que ello añada o quite nada al concepto que ya tenemos completo. Igualmente, cuando nos hacemos la idea de un ente como Inbegriff o suma de toda realidad, como aquello más grande que lo cual nada puede ya concebirse y en el que toda realidad tiene su fuente, el que ese ente exista o no, no añade nada a ese concepto, que ya está completo, exista o no exista ese ente, y, por tanto, no podemos decir que ese ente, si existe, exista por su propio concepto, al menos como pretende hacerlo el argumento ontológico. Simplemente la idea de que algo existe por su propio concepto, no tiene sentido, pues la existencia no es ingrediente del concepto.

Y después de probar que todo argumento a favor de la existencia de Dios o bien se refiere al orden del mundo y acaba viéndose llevado a la cuestión de la relación contingencia-necesidad, o bien empieza por la cuestión de la relación entre contingencia y necesidad y acaba viéndose llevado al argumento ontológico, o bien empieza directamente por éste, es decir, empieza intentando probar que existe un ente necesario por su propio concepto, pero no prueba nada, Kant concluye que "todo el problema del ideal trascendental, el problema de la omnitud de realidad concebida como un ser individual necesariamente existente, se reduce a encontrar o bien un concepto que convenga a la necesidad absoluta, o bien algo que sea necesario por su propio concepto. Si una de ambas cosas es factible tiene que serlo también la otra, ya que la razón sólo reconoce como absolutamente necesario acquello que es necesario por su propio concepto. Ahora bien, las dos cosas sobrepasan por entero cualquier esfuerzo por grande que sea, que pretenda dar satisfacción al entendimiento sobre este punto, e incluso cualquier tentativa para tranquilizarlo en relación con tal incapacidad suya. La incondicionada necesidad que nos hace falta de modo tan indispensable como último sostén de todas las cosas constituye el verdadero abismo para la razón humana. La misma eternidad está muy lejos, a pesar de la terrible sublimidad con que la describe el poeta Haller, de producir en nuestro ánimo tanta impresión de vértigo. En efecto, la eternidad se limita a medir la duración de las cosas, pero no las sostiene. No podemos ni evitar, ni soportar el pensamiento de que un ser que nos representáramos como el supremo entre todos los posibles, 
aquello más grande que lo cual nada puede ya concebirse, se dijera a si mismo: Existo de eternidad a eternidad; nada hay fuera de mí, excepto lo que es algo por voluntad mía, pero ¿de donde vengo yo? Aquí no encontramos suelo firme; sino que tanto la mayor perfección como la más pequeña quedan en el aire sin apoyo ninguno frente a la razón especulativa, a la que nada cuesta hacer desaparecer sin el menor obstáculo tanto una como otra" " y a la que nada cuesta, por supuesto, hacerse desaparecer también sí misma.

La razón da, pues, consigo como protagonizando ella misma el no-ser de lo absoluto, como consistiendo ella misma (por lo menos en sentido especulativo) en el no-ser de lo absoluto y puesta, sin embargo, en el lugar de un absoluto que ella no puede ser. La razón es un no-ser del absoluto y un no-absoluto que es un absoluto, un no-ser de lo absoluto, en el que lo absoluto consiste. En el no-ser de sí mismo no consistir sino en sí mismo: éste es el elemento más básico de la noción hegeliana de concepto. El concepto, en cste caso, en el caso de la razón ilustrada moderna, se tiene él a sí mismo absolutamente, en su ultimidad. Ésta es la noción de lo Absoluto de Hegel.

Al principio de su Doctrina de la ciencia de 1794, Fichte se refería a esto mismo, argumentando que, cuando enunciamos el principio de identidad $\mathrm{A}=$ $\mathrm{A}$, estamos dicienclo que, si $\mathrm{A}$, entonces $\mathrm{A}=\mathrm{A}$. Pero cuando decimos que yo $=$ yo, no estamos diciendo que, si yo, entonces yo $=$ yo. Pues esa condición ha llegado ya siempre demasiado tarde. El yo siempre se ha presupuesto ya, subyace a esa condición y la sostiene. El yo se subyace, por tanto, a sí como contingente y subyace a cualquier suposición de contingencia de sí. Es, por tanto, un absolutamente otro de sí que no es sino él mismo y que subyace siempre a cualquier condición, siendo, por tanto, incondicionado ${ }^{9}$. En este no consistir sino en el absoluto más-allá de sí es donde tanto para Kant, como para Fichte, como para Hegel radica, por lo demás, la libertad, con el carácter incondicionado que ésta ofrece.

Pero para entender a Hegel, aparte de mirarlo desde Grecia, desde el Cristianismo y desde Kant, es igualmente importante mirarlo desde un cuarto lugar, desde la ciencia moderna. En la Fenomenología del espíritu, que es lo que mejor conozco de Hegel, están particularmente presentes la Biología naciente y la investigación biológica y fisiológica en general, que Hegel logra mirar en la misma dirección en que después se han desarrollado. La afirmación de que

8 KANT, $K r V$, A $612 \mathrm{~s}$.

9 Cfr. FICHTE, Joh, Gottob, Grundlage der gesamten Wissenschaftslehre (1794), Hamburg: Felix Meiner Verlag ,1979, págs, 11. Para la interpretación que estoy haciendo de ello, véase también FICHTE, Johann Gottlieb, Vierter Vortrag der Wissechafislehre (1805), J. G. Fichte-Gesamtausgabe, II,9, Stuttgart: Friedrich Frommann Verlag, 1993, hora 20, págs. 271. 
el yo es reducible a su cerebro y de que éste es reducible a materia inorgánica y a la organización de ésta, expresa, según Hegel, quizá el punto más alto de aquello en que tiene que consistir, de aquello a que se ve llevada y de aquello a que está llamada a llegar la razón científica moderna (la "razón observadora" moderna). Ésta busca encontrarse a sí misma en todo, el dar autónomamente razón de todo, también de sí misma como quedando ella ahí delante para sí misma. Y además ese hallazgo, el más alto, de la "razón observadora" tiene que tener, naturalmente, un reverso tecnológico, pues si el yo ha de poder reducirse a lo otro y aun absolutamente otro de sí, es decir, a lo que en definitiva no es él y le queda a él ahí delante como lo otro de él (como cosa, como materia, como una determinada configuración de la materia que ahí está ya incluso sin él), resulta también que en lo absolutamente otro de mí no habría de haber sino yo e incluso eso absolutamente otro de mí que soy yo (mi cerebro, materia orgánica reducible a elemento inorgánico) no ha de acabar siendo sino proyecto del yo. Éste habría de dominar incluso su propia base orgánica, de la que emerge y a la que se reduce ${ }^{10}$.

Pero justo entonces, por ambos lados, por el lado la conciencia científica y por el lado de la conciencia tecnológica, la conciencia moderna, la conciencia fáustica, es la "conciencia desgraciada", es conciencia religiosa, o fiel trasunto de la conciencia religiosa. Pues la conciencia religiosa entiende que lo propio de ella, el lugar donde de verdad ella es ella, es en lo absolutamente otro de ella respecto de lo cual ella resulta momento evanescente, donde ella se suprime y supera, siendo esa superación su suprema conquista y en lo que ella propiamente se tiene, a la vez que eso otro parece rechazarla.

En la Ciencic de la lógica, la referencia, a mi juicio, más importante no es a la Biología, sino a la Matemática y a la Física teórica moderna. Hegel conoce muy bien el cálculo diferencial y hace suya la limpieza que Lagrange y Cauchy ${ }^{11}$ llevan a cabo de la situación en la que los creadores del cálculo diferencial (Newton y Leibniz) lo dejan, quitándole todas las adherencias físicas y metafísicas hasta dejarlo reducido a conceptos puramente matemáticos (o casi). Hegel en todo caso está al tanto de esa limpieza, pues hace un uso directo de los textos de Lagrange. Y supongo que cuando al final de su vida alcanza a revisar la "doctrina del ser" de la Ciencia de la Lógica, conoce también los textos de Cauchy. Y es en las obras de Lagrange y Cauchy y, por tanto, en el

10 Cfr. HEGEL, G. W. F., Fenomenología del espiritu, Valencia: Pre-textos, 2006, sobre todo la sección linal de la primera parte y la sección inicial de la segunda parte del cap. V.

11 LAGRANGE, Joseph-Louis, Théorie des fonctions analytiques (1797), CAUCHY, Augustin-Louis, Cours d Analyse a l'Ecole Polytechnique (1921); CAUCHY, Augustin-Louis, Résumé des' leçons sur le calcul infinitésimal (1823); HEGEL, G. W. F., Wissenschaft der Logik , ed. George Lasson, Hamburgo: Felix Meiner, 1967, tomo I, págs. 278 ss. 
calculo diferencial, tal como ha quedado en la Matemática y como instrumento matemático de la Física, en clonde Hegel ve la versión más pura de la idea platónica de que nada es sin ser lo otro y aun lo absolutamente otro de sí mismo. Lo finito no es sin que el más allá de sí, lo infinito, le pertenezca, sea él. Y lo infinito no es, es decir, lo infinito sólo sería algo finito frente a lo finito, si el más-allá de él, esto es, lo finito, no fuera él. Y éste es cl genuino concepto de lo infinito o, si se quiere, el genuino concepto de lo infinito bueno, no del infinito malo que no acaba siendo sino finito. Pero conforme al Cristianismo y, si se quiere, conforme a la versión que Lagrange y Cauchy acaban dando al calculo diferencial, el infinito se ha dado ya siempre a lo finito, lo finito es, porque lo infinito, haciéndose finito, eleva lo finito a él; sin quedarse en su infinitud, pues si se hubiera quedado en su infinitud sería lo infinito malo en el sentido dicho.

Y naturalmente, este poner juntas la conciencia religiosa, la conciencia científica y tecnológica y la idea de infinito en la forma que cobra en la limpieza que Lagrange y Cauchy hacen de la conceptuación del cálculo diferencial, empicza a sonar a un inmenso "disparate". Y creo que a Hegel no se le entiende, si, finalmente, aparte de mirarlo desde los cuatro sitios que he dicho, no se le acepta como este inmenso "disparate" goyesco, que se comporta como un fascinante juego de espejos a lo Borges, que al principio confunde, que nos hace muchas veces protestar, pero que cuando uno se maneja en él empieza a transformársele en el lugar en donde mejor que en ninguna otra parte la conciencia moderna y contemporánea puede verse a sí misma en sus múltiples facetas e incluso consistiendo en sus extremos.

\section{EL RETORNo de HEGel}

No es de extrañar que, si podemos decir que las representaciones cristianas traídas a su concepto griego, he ahí la conciencia ilustrada moderna, tal como ésta se cxpone a sí misma en Kant, y tal como Hegel lleva a concepto lo que sucede en Kant, si podemos decir eso, todos estos elementos precisamente en la articulación que Hegel les da y, por tanto, el mismo $\mathrm{Hegcl}$, con muy distinta fortuna, a veces eclipsado por Kant, a veces eclipsando él a Kant o al menos haciéndose mutuamente sombra, reaparezcan y hayan de ser reconsiderados cada vez que esa conciencia se vuelve problcma para sí misma.

Es lo que sucedió cuando en el primer tercio del siglo XX el horizonte histórico se oscureció. La reconsideración que se hizo de las bases de la sociedad y de la cultura ilustrada en general, incluyendo la ciencia y la técnica, acabó en parte quedando arrastrada ella misma por la crisis de civilización de los años 30 del siglo XX, que siguió a la crisis económica de 1929. Pero, en parte, de esa reconsideración de las bases de la cultura ilustrada, o de de esas bases de la 
cultura ilustrada tal como resultaron de esa consideración, y tras la experiencia de la catástrofe, es de lo que hemos vivido, casi hasta el presente.

Pero hoy el mundo de posguerra se ha dejado atrás a sí mismo ${ }^{12}$. Y en nuestro presente las bases de ese mundo que se ha ampliado súbitamente y que cultural, política y religiosamente se sigue queriendo ilustrado, y que fácilmente podría convertirse de nuevo para sí mismo en catástrofe, parecen otra vez no estar seguras. Nuestra situación parece plantear la necesidad y exigencia general de entendernos acerca de la articulación de los elementos que están a la base de la existencia moderna, acerca de aquella articulación de Grecia, religión cristiana, razón ilustrada (tal como ésta se expresa en Kant) y ciencia y tecnología, que Hegel tan magníficamente analizó. Pues a causa de este nuevo extrañamiento de la cultura ilustrada, ahora ampliada, respecto de sus propias bases teóricas y prácticas, se diría que de forma un tanto súbita ha quedado desbordado el pensamiento de posguerra del que vivíamos, dependiente del de principios del siglo $X X$.

$\mathrm{Y}$ en este contexto Hegel retorna exigiendo ser repensado precisamente desde lo que hasta ayer era actual, pero se diría que con vistas a un mañana que agrede ya sin concepto claro y respecto al que, por tanto, urge entendernos o reabrir posibilidades de autocomprensión. Y no es que la filosofía haya de constituir el centro de ello, sino que no puede evitar verse metida en ello. Y en ésas estamos. Hegel retorna y, sin embargo, diríase que ese retorno resulta imposible. Veamos por qué.

\section{El imposible RETORNo de HeGEL}

Decía Habermas en los años 80 que la filosofía contemporánea en sus cuatro corrientes principales, que han sido la filosofía analítica del lenguaje, la fenomenología, la teoría crítica y el posestructuralismo francés, (1) se había acabado convirtiendo en un pensamiento posmetafísico, (2) se caracterizaba en todas ellas por un giro lingiiístico, (3) ambas cosas habrían llevado a entender la razón siempre en un sentido "situado" y contextual, y (4) en todas esas corrientes se había producido la inversión afirmada por el marxismo y el pragmatismo de las relaciones entre teoría y praxis $^{13}$.

Pues bien, los rasgos (3) y (4) son rasgos que se invierten fácilmente. El carácter situado de la razón es tal que la situación en la que se encuentra el pensamiento ilustrado hoy es quizá la de tener que decidir sobre su propia incondicionalidad ( $y$ en lo que sigue me voy a fijar sobre todo en este aspec-

12 Cfr. HOBSBAWM, Eric, Age of Extremes, The Short Twentieth Century, London: Michael Josehp, 1994.

13 HABERMAS, Jürgen, Penstamiento postmetafisico, lladucción de Manuel Jiménez Redondo, Madricl: Taurus, 1990, págs. 38 ss. 
to). Y lo mismo puede decirse respecto del último rasgo: la inversión de las relaciones entre teoría y práctica se reinvicrte en cierta manera, a la vez que se confirma, cuando una de las necesidades prácticas más perentorias es la de buscar orientaciones en una situación en la que se oscurece casi por completo el sentido de la incondicionalidad con que se presenta la razón teórica y la razón práctica modernas.

No sucede así con el rasgo (1), es decir, con el carácter posmetafísico del tipo de pensamiento en el que nos movemos. Y, por tanto, tenemos que, cuando Hegel retorna, exigiendo ser pensado desde el lugar donde estamos, que es el de un pensamiento de posguerra desbordado y evanescente, eso que retorna se diría que no podemos tomarlo en serio. Pues precisamente en el punto en que la razón moderna destruye la idea de absoluto, en el punto en que Kant destruyc el argumento ontológico y saca las consecuencias de ello, o también podemos decir: en el punto en que la razón moderna se encuentra a sí misma convertida en el no-ser del absoluto, Hegel practica una inversión por la que ese pensamiento que tiene por objeto al absoluto que queda borrado, un pensamiento que convierte a la razón en un absoluto si acaso metafórico, se convierte en un pensamiento que tiene por protagonista a lo absoluto, en el sentido de que éste, donde precisamente es, es en el no-ser de sí mismo; el absoluto es negativiclad referida a sí misma, pero ya absolute, absolutamente, una absolute sich auf sich beziehende Negativitat. El retorno de Hegel implica el retorno de esta metafísica. Y ello discurre decididamente en sentido contrario a todo el pensamiento contemporáneo, que es el que provoca cse retorno. De modo que, conforme a ese pensamiento, no hay tal absoluto ni hay tal metafísica, ni tiene tampoco ningún sentido el vuelco que Hegel da a la borradura kantiana de lo absoluto. Y ello aun prescindiendo de que la pretensión de incondicionalidad de la razón ilustrada, pretensión que desde luego buena parte de ese pensamiento posmetafísico sigue todavía entablando, puede resultar ser también ilusoria, puede resultar ser una euestión más de hecho que de derecho ${ }^{14}$; al pensamiento posmetafísico contemporáneo le es inherente en todo caso la duda sobre csa pretensión.

De este carácter posmetafísico o antimetafísico del pensamiento contemporáneo, totalmente contrario al carácter del pensamiento de Hegel, podemos percatarnos particularmente bien si reparamos en una de las obras más relevan-

14. Cfr. sobre toda esta cuestión; HABERMAS, Jürgen, Teorfa de la acción comunicativa (1981), trad. de Manuel Jiménez Redondo, Madricl: Trotta, 2010, principalmente el cap. II „Teoría de la racionalización de Max Weber “; también el cap. I „Accesos a la problemática de la racionalidad", y asimismo HOLLIS Martin, LUKES, Steven (eds.), Rationality and Relativism, Oxford: Basil Blackwell, 1982. En un sentido distinto cfr. también HABERMAS, Jürgen, $E l$ discurso filosófico de la Modernidad, Buenos Aires, Madrid: Katz Editores, 2008. 
tes, quizá la más relevante entre las que fueron protagonistas de aquella reconsideración de los supuestos de la conciencia ilustrada moderna, que tuvo lugar en el primer tercio de siglo XX. Me refiero a Ser y tiempo de M. Heidegger.

Ser y tiempo puede muy bien entenderse en este sentido como formando parte de la herencia kantiana, es decir, como una aclaración conceptual o como un poner también en primer plano la experiencia central que hace de sí la conciencia moderna en la Crítica de la razón pura de Kant como razón finita, como razón sin fondo, como razón que ocupa el lugar de un incondicionado que ella no puede ser y, por tanto, como un incondicionado que, al carecer de base, se diría que parece quedar dispuesto para ser absorbido por toda clases de Condicionados y condicionamientos, por más que el libro de Heidegger pretenda, quizá impotentemente, señalar en dirección contraria.

Y esta conciencia de finitud que se diría que comporta también a la larga (eso es al menos lo que se ha visto en el pensamiento del siglo XX) un deshacerse o por lo menos un quedar en duda la pretensión de incondicionalidad de la razón ilustrada, parece que va muy esencialmente ligada también al segundo rasgo del pensamiento contemporáneo del que habla Habermas, al giro lingiilistico por el que se caracteriza casi todo él. Ello es expresamente así en el caso de Verdad y método de Gadamer, en el que a la conciencia metódica ilustrada la verdad más importante ha de venirle quizá tambiér de otro sitio ${ }^{15}$. Ello es también así, por otro lado, en el giro semiótico que en La voz y el fenómeno Derrida lleva a cabo de la fenomenología trascendental de Husserl. Y como es de sobra sabido, en el Tractatus de Wittgenstein la elucidación de la forma lógica por la que el lenguaje puede pretender ser representación del mundo, se revela como una pura ilusión en cuanto se hace patente que dicha elucidación tiene que estar hecha desde un más-allá de ella, esto es, tendría que estar hecha mediante un decir que precisamente la elucidación de la forma lógica muestra como imposible. El otro lado del límite no sólo se rehúsa a la conceptuación de la conciencia finita sino que, al rehusarse, vuelve imposible toda metafísica de la conciencia finita por la que ésta pudiese dar conceptualmente alcance a cualquier pretensión de incondicionalidad. Las formas de la razón ilustrada quedan, pues, entregadas a la contingencia de su propia génesis y devenir históricos. No son sino jucgos de lenguaje que a nosotros nos ha sucedido habitar. Por tanto, el Tractatus de Wittgenstein y todo lo que de él se sigue y se ha seguido sería la conciencia reflexiva y bien formada de la completa imposibilidad del tránsito del capitulo último de la Fenomenología del espiritu a la Ciencia de la Lógica. No hay la menor posibilidad de que la experiencia histórica de la conciencia acabe mostrándose como conteniendo una metafísica que dé finalmente alcance

15 Cfr. GADAMER, Wahrheit und Methode, Tübingen: J. C. B. Mohr (Paul Siebeck), 1986, Einleitung, págs. $1-5$. 
a la propia pretensión de incondicionalidad reiteradamente desmentida. Aparte de que csa pretensión tal como en la Ciencia de la Lógica se desenvuelve es ya problemática por tener que ignorar el vuelco que respecto de la Lógica aristotélica se produce a fines el siglo XIX y principios del XX con la obra de Frege y Russell, de la que Wittgenstein depende.

Por tanto, el retorno de Hegel desde y al pensamiento contemporáneo, parece que, conforme a lo que es el propio sentido del mejor pensamiento contemporáneo, excluye expresamente todo compromiso con ese tránsito de la Fenomenología del espíritu a la Ciencia de la Lógica. En eso parece estarse tan de acuerdo en las distintas corrientes del pensamiento contemporáneo, que éste suele contener casi siempre, casi como un ingrediente obligado, la ceremonia de un expreso puntapié a Hege ${ }^{16}$. Pero entonces, surge la duda de si el relorno de Hegel, al haber de ser un Hegel sin metafísica, no es poco menos que nada, o simplemente nada. Pues si se excluye ese compromiso con esta articulación metafísica del pensamiento hegeliano, no se sabc muy bien en qué consiste o pueda consistir ese retorno de Hegel. Ese retorno es quizá una nostalgia historicista de un concepto que en la obra de Hegel se hizo de sí esa razón kantiana que históricamente se puso durante un instante en el lugar de un incondicionado que ella no podía ser y que precisamente por eso desde entonces acá se nos ha disuelto más o menos nietzscheanamente, o no nietzscheanamente, quizá postmodernamente, en toda clase de historias, genealogías y condicionamientos. O por lo menos amenaza con disolverse.

Y la verdad es que la recepción de Hegel, tal como Hegel es, en el contexto de un pensiero debole, por así decirlo, chirría por todos lados. Y hace pensar en si la reconsideración del concepto hegeliano de la razón ilustrada moderna no pasa tal vez de ser una última perplejidad de una profesión como la nuestra de filósofos, cuyo cometido está llamado quizá en el mejor de los casos a rezumarse en campos de la cultura de pretensiones más atemperadas o muchísimo más atemperadas que las de la metafísica de Hegel (y no ya sólo de pretensiones más atemperadas que las de la metafísica de Hegel sino de pretensiones más atemperadas que las de la filosofía trascendental de Kant o que las de las reformulaciones contemporáncas de ésta, o incluso que las pretensiones mucho más modestas de la "lógica filosófica" de la filosofía analítica del lenguaje).

La primera cuestión que he planteado, la de que el retorno de Hegel chirría en el contexto del pensamiento de una época que en conjunto se entiende a sí mismo como pensamiento posmetafísico, para el que la idea de absoluto simplemente se borra, se le deshace en términos de radical finitud o se le vela definitivamente en negro, como decía Adorno, viene expresamente planteada

16 Si bien es verdad que en esa cercmonia queda a veces bastante claro que Hegel simplemente no está leído. 
por Heidegger (por lo menos en cierto modo, según vamos a ver). Y entiendo que en este sentido Ser y tiempo de Heidegger es un texto muy representativo del pensamiento contemporáneo, un texto en el que este encontrarse de la razón kantiana queda brillantemente traído a concepto, expresamente contra Hegel y en dirección se diría que totalmente opuesta a la de Hegel. Y me parece que, para nosotros, Nietzsche, a través del pensamiento francés, ha venido siempre más o menos interpretado desde ese texto. El absoluto se reduce a completa finitud y ésta parece acabar volatilizando o en todo caso amenaza con volatilizar cualquier noción de incondicionalidad.

\section{TIEMPO y CONCEPTO: FENOMENOLOGIA DEL ESPÍRITU Y SER Y TIEMPO}

Heidegger plantea esta expresa discusión con Hegel en forma sobre todo de una discusión de la relación que Hegel establece entre tiempo y concepto. Si nos aclaramos sobre esto, podríamos también abordar la segunda cuestión que he planteado, la relación de ello con el lenguaje, con la palabra, la cual es, en términos de Hegel, el espíritu ejerciendo su derecho de soberanía ${ }^{17}$. Es lo que pensaba hacer en esta ponencia, cuando di el titulo a los organizadores del presente congreso, pero por razones de tiempo me voy a limitar sólo a esta primera cuestión, a la de la relación entre tiempo y concepto.

Naturalmente, en relación con esta primera cuestión, no tengo nada que sentar ni establecer, sino sólo algo que proponer como tema de discusión, como tesis que se sugiere, pero que se retira en caso de mejor parecer. Y lo mismo ocurriría con la segunda cuestión.

Pues bien, por entrar sin más en el tema, diré que yo cada vez soy menos capaz de distinguir, en lo que se refiere a bases, entre la Fenomenología del Espíritu de Hegel y Ser y tiempo de Heidegger, y he traducido, comentado e introducido ambas obras, por más que no me dejen publicar la segunda, que doy ya por convertida en un legado testamentario. Eso quiere decir que cada vez soy menos capaz de distinguir entre estas dos obras fundamentales del pensaniento moderno, la segunda de ellas determinante (o en todo caso muy representativa, así al menos me lo parece) de ese pensamiento contemporáneo, precisamente en el que Hegel críticamente reaparece hoy. El último parágrafo de Ser y tiempo es muy breve, lleva por título "La analítica existencial-temporal de la existencia y la pregunta de ontología fundamental por el sentido del ser en general" (traduzco Dasein por el significado corriente que el término tiene en alemán, existencial, que en Ser y tiempo no es desdicho por el empleo terminológico

17 HEGEL, G. W. F., Jenaer Realphilosophie, edit. Johannes Hoffmeister, Hamburg: Felix Meiner, 1969, págs. 182 ss. HEGEL, G. W. F. Enciclopedia filosófica para los áltimos carsos de bachillerato, trad. de Manuel Jiménez. Redondo, Valencia: MuVIM, 2007, $\$ \$ 159$ s. 
que Heidegger hace de este término en esta obra, sino que al contrario creo que queda confirmado por él hasta el punto de que en los cscritos que forman el entorno de Ser y tiempo Heidegger recurre al término latino para explicar el término alemán Dasein). Ni que decir tiene que la analítica de la existencia, la analítica de este ente para el que en su ser se trata de su propio ser, es decir, de nosotros mismos, de la existencia que es para cada cual la suya, es la ciencia de la experiencia que hace de sí la conciencia moderna, es algo así como la Fenomenología del espíritu, la cual también acaba en la pregunta de ontología fundamental por el sentido del ser en general que es la Ciencia de la Lógica. Los papeles que desempeñan la Fenomenología del espíritu y Ser y tiempo en los respectivos proyectos de Hegel y de Heidegger son paralelos, si bien Ser y tiempo supone, naturalmente, la Fenomenología del espíritu. Nada tiene, pues, de extraño que el largo parágrafo penúltimo de Ser y tiempo, lleve por título "deslinde, Abhebung, o diferencia entre la conexión ontológico-existencial de temporalidad, existencia y tiempo mundano y la forma en que Hegel entiende la relación entre tiempo y espíritu."

Y lo que Heidegger tiene que decir sobre ello es que Hegel, tanto en la Enciclopedia, como también al final de la Fenomenología del espíritu, en dondc discute la relación entre tiempo y concepto, yerra la temporalidad original, que es la clave de Ser y tiempo. El concepto de tiempo que Hegel emplea es en definitiva el concepto vulgar de tiempo, que es un concepto derivado, un concepto fundado en el concepto de temporalidad original, que Hegel ignora.

Y como conforme al parágrafo final de Ser y tiempo y conforme a todo el sentido del libro, la cuestión de ontología fundamental, la pregunta por el sentido del ser en general, va ligada a esa clave que es el tiempo original, Hegel yerra por completo (al menos de entrada) la cuestión del sentido del ser. Hegel es, si acaso, para Heidegger el gran representante del tipo de ontología que Heidegger quiere deconstruir, que Heidegger deconstruyó supuestamente con éxito, y en los resultados de cuya deconstrucción nos movemos hoy. Si no, la Fenomenología del espíritu de Hegel y Ser y tiempo vendrían a tener un significado similar: ambas obras serían introducciones a la Ciencia de la Lógica, a la ciencia del ser en cuanto ser, en cuanto éste cae en la comprensión de la existencia, siendo la existencia el ente que se caracteriza y viene definido por esa comprensión.

Por lo demás, Ser y tiempo es una discusión con Hegel ya desde la primera frase con que la empieza el libro. El libro da comienzo con una cita de Platón, de El sofista, que, como sabemos muy bien desde hace algunos años, es una especie de eco del curso de 1924- 1925 que Heidegger dedicó a lo que desde el capítulo III de la Fenomenología del espíritu es igualmente el centro del pensamiento de Hegel, la doctrina del ser de El Sofista de Platón. Y lo mismo 
que Hegel, Heidegger no logra mirar a Platón sin ver en Aristóteles lo más especulativo de Platón.

Y sobre la base de este recurso a la doctrina del ser de Platón, ya en ese mismo curso, pero también en el texto de 1922 titulado Phänomenologische Interpretationen zu Aristoteles y en el curso de 1924 sobre Conceptos findamentales de la filosofía aristotélica Heidegger recurre desde luego a todo Aristóteles, pero en lo que se refiere a conceptos que serán determinantes en Ser y tiempo, recurre en especial a algunas partes del corpus aristotélico. A mí me llaman especialmente la atención sus referencias a la Ética a Nicómaco y sobre todo las referencias al libro V de la Metafísica ${ }^{18}$. De ese libro toma los conceptos de lo perfecto, de limite, y de "por mor de lo que", que resultan fundamentales en la estructura tanto de Ser y tiempo como de la noción de sich auf sich beziehende Negativitït (negatividad que se refiere a sí misma) de Hegel.

De modo que, si entendemos que en el caso de Ser y tiempo de Heidegger la representación cristiana (tal como Hegel la entiende por oposición a concepto) viene representada por Kierkegaard y Lutero, de manera semejante a como en Hegel, naturalmente, viene representada sólo por Lutero o principalmente por éste, también podemos decir en relación con Ser y tiempo que la representación cristiana protestantemente radicalizada, que ella misma se ha empujado a hacerse concepto de sí, he ahí la conciencia moderna haciéndose entero concepto de sí en su finitud, tal como esa conciencia da consigo en la obra de Kant: como teniendo por centro la borradura de lo absoluto y el estar en el lugar de lo absoluto. Es el absoluto finito que parece suponer Heidegger.

A decir verdad yo no he visto una diferencia tan grande como la que se da entre Hegel y Heidegger a la hora de referirse a un mismo fenómeno, o, si se quiere, al esencialmente no-fenómeno, a la libertad moderna y a la pretensión de incondicionalidad con la que ésta da consigo misma.

Pero la pregunta es: ¿de verdad hay tanta diferencia?, ¿o no sucede más bien que la diferencia es tan aparente que no hay ninguna, de modo que Ser y tiempo no sería sino una repetición muy incompleta del concepto que Hegel se hace de la finitud de la razón en Kant?

Para ver que no hay tanta diferencia si es que hay alguna, o para ver si la hay o no, o para ver que quizá no hay tanta, hemos de referirnos a la objeción de Heidegger de que, precisamente cuando habla de la relación entre tiempo y concepto, Hegel ignora la temporalidad original que resulta esencial para la pregunta de ontología fundamental acerca del sentido del ser, de suerte que Hegel erraría esencialmente esta pregunta, lo que descalificaría su Ciencia de la lógica, una obra que hoy casi nadie lee, parece ser, pues, que con toda razón. Tal como lo ve Heidegger, Hegel, igual que Platón, considera el tiempo desde 
el ahora, que indefinidamente se re-crea a sí mismo, y así acaba entendiendo el ahora y, derivadamente quizá, también el tiempo indefinido como trasunto de lo eterno. El tiempo es el concepto intuido, cl concepto en su quedar ahí a la vista en su negatividad. El horizonte de la comprensión del ser sería, por tanto, para Hegel el concepto entendido en términos de Platón, lo absoluto, lo eterno. Y para Heidegger, esta manera de ver las cosas se esfuma en cuanto, mirando el tiempo desde la existencia, nos vemos obligados a considerar como horizonte de la comprensión del ser el tiempo en su radical finitud ${ }^{19}$.

\section{LA PREGUNTA POR EL SENTIDO DEL SER}

Empecemos por la pregunta acerca del sentido del ser en general. La verdad es que esta dichosa pregunta por el sentido del ser, no se entiende de por sí muy bien, tal como queda planteada al principio de Ser y tiempo. Pero también es verdad que está muy bien planteada cuando se la mira desde Husserl. Toda conciencia es intencional, cs conciencia-de, un estar-en-algo. Y la fenomenología de Husserl se entiende metodológicamente a sí misma como una perversión de la conciencia natural; la filosofía consiste en que, suspendiendo nuestro natural estar-en-algo, nos volvemos a analizar en qué consiste ello, es decir, en qué consiste el fenómeno, el estar en algo siéndonos ello presente, la conciencia de ello, y, en suma, en qué consiste el eidos, la estructura del sernos presente algo en la modalidad cognitiva, volitiva o afectiva que fuere. Pero, después de dar muchos vueltas, y después de desarrollar así una psychologia rationalis, o capítulos de ella, que incluso puede ser magnífica (como resulta patente si se toman en consideración los trabajos de Husserl, de Scheler y de otros), nos damos cuenta de que una suposición básica, elemental, de todo lo que estábamos haciendo, subyacente en todo lo que estábamos haciendo, y que estábamos olvidando en todo lo que estábamos hacienclo, es que hay un darse cosas y, sobre todo y más primariamente, un haber o darse la conciencia, un haber también conciencia en ese estar la conciencia en ellas en la modalidad cognitiva, volitiva o afectiva que fuere.

El análisis tiene que retroceder y convertirse en la pregunta por este hay, por este haber, en el sentido de de qué conciencia es intención. La pregunta es, digo, de qué conciencia es intención ese hay, ese haber, cuál es la estructura de esa intención y cuál es la estructura del correlato de esa intención, tal como se da en esa intención y a esa intención, que se muestra entonces como la más básica, constitutiva, de la conciencia-de. Pues lo que más elementalmente caracteriza a la conciencia como conciencia de algo o como conciencia reflexiva de sí es precisamente tener esta intención del hay, que cuando se vuelve tema es cuan-

19 Cfr. HEIDEGGER, Martin, Der Begriff der Zeit (1924), Tübingen: Max Niemeyer Verlag, 1995. 
do el mundo como tal y la conciencia en su haberla quedan ante la conciencia como incomprensibles. La conciencia del hay y el hay como correlato de la conciencia destacan aquí en toda su enigmaticidad. Así se abre Ser y tiempo: la conciencia, la existencia consciente, la existencia, es un ente que tiene como intención elemental, base de todas las demás, la intención del hay, del haber, es decir, la conciencia es un ente que se caracteriza por una comprensión del ser y para la que, en su ser, se trata elementalmente de su propio ser, pues esa comprensión del ser se refiere elementalmente al propio haber conciencia, al estar ella siendo ese haber conciencia, al propio haber esa comprensión, que es ella, que ya no se comprende, que rebota contra sí mismo. La pregunta de ontología fundamental por el sentido del ser, es decir, la cuestión del sentido del ser, es la pregunta por el ser en cuanto éste cae bajo la comprensión de la existencia, es decir, en cuanto es correlato de una intención básica, constitutiva del ente que somos y que se es él ese su haberlo sin haberse él puesto.

$\mathrm{Y}$, naturalmente, Heidegger señala que esta pregunta que re-emerge en Husserl fue planteada por los griegos, por Parménides y Heráclito, por Platón y Aristóteles, por los medievales hasta Suárez dependiendo de Platón y Aristóteles, por Leibniz, por Kant en su discusión del argumento ontológico, y, naturalmente, no sólo en ese contexto ${ }^{20}$, y a lo grande había sido planteada sistemáticamente por última vez por Hegel en la Ciencia de la lógica. (Había sido planteado también por Fichte en términos muy similares a los de Heidegger, por ser enteramente paralelos a los de Husserl, pero Heidegger no sabía esto, ya cue los cursos del último Fichte no estaban publicados ${ }^{21}$ ). Para preparar esa pregunta o para preparar el replanteamiento de esa pregunta hay que aclarar la estructura de esa intención que define a la existencia y es esto lo clue Heidegger desarrolla en términos de una analítica del ente que se caracteriza por esa intención, que se caracteriza por una comprensión clel ser. Éste es el libro Ser y tiempo, el que tenemos, que es sólo la primera parte de lo que se anuncia en la introducción.

\section{LA ESTRUCTURA DE SER Y TIEMPO: PRIMERA Y SEGUNDA RONDAS ANALÍTICAS}

Ser y tiempo consta, por así decirlo, de tres rondas analíticas. La primera (\$\$ 11-38) es el análisis del ser-en-el mundo, con tres polos. El primero es el análisis del mundo como entorno y de la mundanidad del mundo con base en la significatividad ( $\$ 11-18)$ y en el contraste de ello con el análisis cartesiano

20) Cfr. HEIDEGGER, Martin, Kants These über clas Sein (1961), en: HELDEGGER, Martin, Wegmarken, Frankfurt: Wiltorio Klostermann, 1978, págs. 439 ss.

21 Cfr. FICHTE, Johann Gottlieb, Vierter Vortrag der Wissechafislehre (1805), J. G Fichte-Gescuntursgabe, II,9, Stuttgart: Friedrich Frommann Verlag, 1993. 
del mundo como res extensa frente a la res cogitans ( $\$$ 19-21), y a propósito de eso sigue un análisis de la espacialidad de la existencia ( $\$ 20-24)$. El segundo polo es la consideración de la existencia como con-ser (Mit-sein) $(\$ \$$ 25-27). Y el tercer polo es el análisis del ser-en como tal (\$\$ 28-34), con dos momentos: el primero es el de dar la existencia consigo echada en el ente que, siendo ella, ella no lo ha puesto, un ente, cuyo estar en sí sin coincidir consigo, consiste en haber de serse, en dar cumplimiento a posibilidades de sí en las que él se entiende o no se entiende, y precisamente éste es el segundo momento del ser-en, el momento que consiste en ser la existencia entender y proyecto. Este ser-en del ser-en-el-mundo es caracterizado por Heidegger como iectata proiectio, como geworfener Entwurf. La articulación de ese entender es die Rede, el discurso, y la Herausgresprochenheit der Rede, el quedar ahí fuera el discurso, el constituir éste the space of reasons, el espacio de la razones y las contra-razones, el hacerse el discurso espíritu existente, es el lenguaje. Y una posibilidad señalada del lenguaje es el lenguaje enunciativo, el quedar así descubierto el ente no sólo en lo que respecta a su significatividad en una red de medios y fines en el estarse entendiendo la existencia en alguna posibilidad de sí, sino el quedar expresamente descubierto el ente en su haberlo (el árbol existe), en su ser de esta o aquella manera (predicación, el árbol es verde) y en su ser él mismo en sus distintos modos de darse (identidad). Es la primera vez que aparece en Ser y tiempo el es como es del enunciado. Sobre la importancia de esta aparición se ha expresado muy bien R. Brandom en su libro Tales of the Mighty Dead ${ }^{22}$.

La segunda ronda analítica $(\$ \$ 39-44)$ consiste en tratar de apresar el todo estructural del ser-en-el-mundo como tal todo, pues hasta ahora lo tenemos un tanto disperso en el análisis que en la primera ronda se ha hecho de sus elementos. Después de plantear en el $\S 39$ de qué se trata en esta segunda ronda: de la cuestión de la totalidad original del todo estructural que es la existencia, Heidegger pasa en el $\$ 40$ al análisis del encontrarse básico que representa la angustia frente al miedo, análisis relacionado tanto con la Retórica de Aristóteles como sobre todo con el análisis que Aristóteles hace de la andreía en el libro III de la Ética a Nicómaco, andrcía o valentía que en Ser y tiempo se convierte en resolución (Entschlossenheit). Es precisamente en el contexto de una referencia a este análisis aristotélico en el curso Los conceptos fundamentales de la filosofía aristotélica donde Heidegger introduce por primera vez la noción de Sein zum Tode, el ser acerca de la muerte, si bien inicialmente como una ocurrencia que Heidegger empieza tomándose a broma, y que sólo se le consolida cuando más tarde entra en análisis de conceptos del libro $\mathrm{V}$ de

22 BRANDOM, Robert B., Tales of the Mighty Dead, Historical Essays in the Metaphysics of Intentionality, Cambridge, Massachusetts: Harvard University Press, 2002, págs. 298 ss. 
la Metafísica, a saber: de las nociones del estar algo acabado, completo, y de la noción de límite.

Conforme a ese análisis que se hace de esa modalidad de miedo que no es miedo (Furcht) de algo por algo, miedo que tenemos a algo por el inal que pueda causarnos, sino que es un miedo a nada por nada (Angst, angustia), Heidegger llega a la conclusión que es el encontrarse que representa la angustia el que pone a la existencia ante el todo estructural que buscábamos. El ante qué de la angustia es el ser-en-el mundo como tal. Ese estado de ánimo consiste en quedar la existencia ante sí misma en el modo de revelarse ésta como una amenaza contra sí misma, por tanto, como un radical amenaza de nosotros mismos contra nosotros mismos, ante la que salimos corriendo con terror de la soledad, del vacío y del hastío, buscando conversación y entretenimiento en el ser y el con-ser dentro del mundo. En la angustia la existencia está ante la propia apertura del mundo, le viene abierta su propia apertura, le queda abierta, por tanto, la significatividad (como tal) del mundo, pero le queda abierta en la forma de absoluta extrañeza, y en su carácter de unheimliches, es decir, de que su propio ser, su estar-en-el-mundo, nunca es para la existencia su casa (como ya habían dicho siempre las religiones universales), la existencia pertenece a otro sitio que no tiene nombre, pues su centro es la apertura desde la que se define todo sitio sin estar en ninguno, a no ser que al no-lugar que es constitutivo de la existencia se lo conciba como siendo un duplicado ridículo de lo intramundano de este mundo y le llamemos el otro mundo; esa idea de otro mundo no es sino figura, representación de la absoluta otreidad de sí con la que la existencia da aquí. Y el carácter de unheimliches, de no-casa, con el que la existencia da consigo en la angustia, lo es también en el sentido de lo siniestro, lo kafkiano, el complicado vacío en el que la propia existencia consiste y en el que se pierde o puede perderse.

Y aquí aparece una hay, un haberlo, un es, constitutivo de la propia existencia que es distinto del es enunciativo (del árbol en su haberlo, del árbol en su ser de esta a aquella manera, o del árbol en su ser precisamente este mismo árbol o el mismo árbol), es decir, aparece un hay, un es que no es el es de la enunciación, pues no se refiere a nada con lo que podamos encontrarnos dentro del mundo, pero que le subyace, es el propio hay que la existencia se encuentra siendo en su apertura (hay existencia y la existencia es ese hay), que no puede quedar articulado en forma de un sujeto gramatical y un predicado, o que, al quedar articulado en forma de un sujeto gramatical y un predicado, parece desbordar a la vez esa forma y desbordar cualquier determinidad, pues la oración no puede referirse a nada señalable o determinable como perteneciendo a una determinada clase de entes, sino a ese punto en el que, para la existencia, 
todo ente parece escapar, y también la existencia parece escapar a sí misma, en el que ésta no se refiere a nada ${ }^{23}$. Como ya quedó claro en las Lecciones de filosofía primera de Husserl tanto la intención constitutiva de la existencia, lo que Heidegger llama la comprensión del ser, como el correlato de esa intención o el contenido de esa comprensión ni son nada simple, ni tienen por qué ser nada simple, sino que se pueden revelar como un contex to de elementos incluso difíciles de articular entre sí, como, por lo demás, queda claro en Ser y tiempo. Pues lo original, dice Heidegger, no tiene ni mucho menos que ser simple.

Pero dejemos esto y prosigamos. Analizando en estos términos el ser-en-el mundo como tal, esto es, analizando el todo estructural de la apertura de la existencia que se queda él a sí mismo delante en el eneontrarse que es la angustia, la existencia se revela como cuidado (Sorge, en latín cura). Las referencias a San Agustín, a Pascal y al Criticón de Gracián (en donde el cuidado queda en el centro de la existeneia ${ }^{24}$ ) son aquí evidentes, a pesar de que en Ser y ticmpo la referencia expresa sea a unos versos latinos. La existencia es un por-delantede-sí en el ser-ya-en, a vueltas consigo y con las cosas.

A todo esto sigue en Ser y tiempo el parágrafo 43 y el magnífico parágrafo $44 \mathrm{cn}$ el que de lo que se trata, lo que se busca, es aclararse sobre la problemática relación entre el sentido del ser o la comprensión del ser que tiene como correlato el es del enunciado o concepción tradicional de la verdad, y el sentido o comprensión del hay, del haberlo, del es que tienc como correlato el haberlo, el hay, el es del mundo, y, por tanto, el hay, la apertura que se es la propia existencia, verdad original ésta (Heidegger la llama aletheia) de la que la verdad del enunciado no sería sino una derivación. Esos dos es, esos dos hay, tienen que ver con un no-ser, que es entonces la clave del miedo, de la huida, de la no-casa, de lo siniestro, etc., que se analiza en esta segunda ronda. El primero tiene que ver con el no-ser del hay del mundo, porque no es el hay de ente alguno, o si se quiere: porque es el hay de la existencia que al verse ante sí se ve ante nada, ante el vacío o claro de su apertura, ante la amenaza de ser tragada por sí. Y el segundo tiene que ver con el hay o es del cnunciado (del enunciado de existencia, del enunciado predicativo y del enunciado de identidad) que tampoco parece ser nada sino un diferencia que acaba no siendo diferencia, que no es sino la cosa una de que se trate en su quedar csa cosa a la vista. Ya Aristóteles dice al principio de De interpretatione

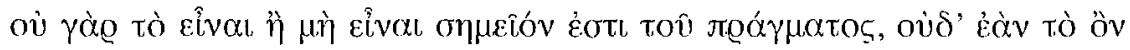

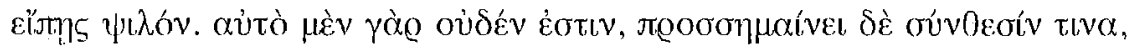

23 Cfr. HEIDEGGER, Martin, „,Qué es Metafísica ?“, trad. de Xavier Zubiri, Madrid: Cruz del Sur, 1963.

24 GRACIÁN, Baltasar, El Criticón, ed. Santos Alonso, Madrid: Ediciones Cátedra, 1980, "Crisi nona: Moral anatomía del hombre“, pág. 201. 


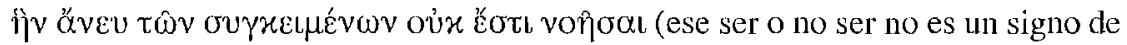
una cosa real, ni aun si dices meramente lo que es, por sí mismo no es nada sino que añade el sentido de una cierta composición que no puede pensarse sin los componentes, pues que acaba rezumándose en ellos, en el quedar ellos a la vista como constitutivos de la cosa).

En este doble no-ser consisten, pues, el haber mundo y la existencia del lenguaje, es decir, de este doble no-ser depende la existencia de la clase de ente que somos.

Y después de esta discusión se diría que acaba Ser y tiempo, pues es hasta açuí hasta donde el libro hoy se lee. Las interpretaciones hoy más serias de Heidegger, las hechas desde la hermenéutica, por un lado, y, por otro, las hechas desde la conexión entre pragmatismo americano y filosofía analítica, es decir, desde la tradición de pensamiento proveniente de Quine, llegan hasta acuí, no se adentran en la tercera ronda analítica que se inicia en el $\$ 45$ de Ser y tiempo.

\section{La ESTRUCtURA DE SER Y TIEMPO: TERCERA RONDA ANALÍtICA}

La tercera ronda analítica de Ser y tiempo, que es, a mi juicio, la más importante del libro, como bien se indica en el propio título de él, se inicia con una pregunta muy escolar ( $\$ 46)$, a saber: nos preguntábamos por el seren-mundo como tal, por el todo estructural del ser-en-el-mundo como tal todo, cuyos elementos habíamos analizado en la primera parte, y, basándonos en ese señalado encontrarse elemental que es la angustia, hemos supuesto que en ese encontrarse la existencia quedaba ante sí misma como un todo y se huía. La existencia quedaba delante de ese todo que es ella misma. Pero ¿de verdad ese todo se ha quedado alguna vez delante a sí mismo? Pues en la primera ronda, en el análisis del momento del ser-en que es el entender, se ha dicho que la existencia era proyecto, estar siempre en algún asunto a vueltas con las cosas, consigo misma y con los demás como estando en algún poder-ser de sí mismá. La existencia consiste en un Sein-können, en un poder-ser, en estar siempre en algún poder-ser o haber-de-ser suyo, en estar a vueltas con posibilidades de sí. Y en la segunda ronda se ha dicho que la existencia es un por-delante-de sí. Y la cuestión es cuándo está completo un ser que consiste esencialmente en posibilidades de sí y en estar o ir por clelante de sí. Porque mientras ese ente existe, nunca está completo, pues siempre le quedan posibilidades por realizar, no ha llegado al cabo de sí, e incluso puede suceder que esas posibilidades no sean las más irrelevantes de él. Y cuando ya no le queda ninguna posibilidad por realizar, no es que esté completo, sino que ya no está, pues es un ser que precisamente consiste en posibilidades de sí. La existencia, mientras es, no está acabada. Y cuando está acabada, cuando ya está entera y completa y no hay 
más, cs que ya no es. Luego nunca podemos tenerla delante como un todo que consista en estarse siendo.

Pero sí la teníamos delante como ese todo que se está siendo, como un todo que es en cada caso el mío. Porque si la existencia consiste esencialmente en posibilidades de sí, la existencia ha dado siempre ya con una posibilidad de sí que en cicrto modo la delimita y la acaba, que es ese acabamiento que ticne que ver conl lo más elemental de la apertura en que consiste. La existencia da en la angustia con la apertura del mundo como más allá de todo ente, como nada del ente, como nada de sí. Es decir, en cuanto consistienclo en posibilidades de sí, la existencia da consigo en la angustia como posibilidad de también no ser, de también no serse. Esta posibilidad, por así decir, circunscribe su esencia (es su límite, su peras que la convierte en un todo acabado teleion). Es, por supuesto, este poder no serse el que, ni que decir tiene, está también a la base de la libertad, del poder optar por ser algo o no serlo. A la vez que, tratándose de un ser que consiste en posibilidades de sí, la existencia es siempre la posibilidad e inminencia de quedar cancelada en este más allá de sí en el que ella consiste ${ }^{25}$.

$\mathrm{Y}$, si embargo, en su darse la espalda, en su huida de aquello en lo que propiamente consistía, en el ocultar la angustia y el hastío que subyace siempre en el fondo de la existencia, la existencia se está siempre estructuralmente llamada a quedarse ella misma referida a ese más-allá de sí misma en que clla elementalmente consiste, sólo desde el cual -piensa Heidegger- puede haber algo importante en la cxistencia, puede estar ésta en su centro.

En la primera ronda analítica la existencia se revelaba como ser-en-elmundo. Y en la segunda ronda el todo estructural del ser-en-el-mundo se revelaba como cuidado. Ahora en la tercera ronda tenemos que el cuidado se revela como un estar referida la existencia a la posibilidad más radical suya que circunscribe su esencia, a la posibilidad de su no-ser, que es a la vez un estarse llamando siempre la existencia a abrazar esa posibilidad desde la que la existencia se pone someramente en su propio centro. Y vemos, por tanto, que, dado que, por lo menos ya desde la segunda ronda analítica, estábamos considerando a la existencia desde aquí, la existencia se nos estaba revclando ya siempre como tiempo, como un venir que no es sino un abrir lo que ya sicmpre se era siéndose así presente: una nada que se recuerda desde nada y viene a sí desde nada, quedando así a la vista la apariencia del mundo o apariencia de la positividad, el fugaz brillo del mundo y de sí, el fugaz brillo del

25 Esta relación o mismidad entre la libertad y el consistirse la existencia en la posibilidad de también no ser queda subrayada asimismo por Hegel en su artículo de 1803 "Über die verschiedene Behandlungsatten der Naturrechts", Georg-Wilhelm-Friedrich Hegel, Werke 2, Jenaer Schriften (1801-1807), Frankfurt: Suhrkamp, págs. 475 ss. 
hay en el retorno de éste a su esencia. La existencia es radicalmente ese advenir "sidente" (gewesende) ${ }^{26}$ que se es así presente, ya lo sea en el modo de serlo propiamente, ya lo sea en el modo de huirse. El ser-en-el- mundo (primera ronda) lo estábamos entendiendo como cuidcudo (por delante de sí ser-ya-en en el estar a vueltas consigo y con las cosas) (segunda ronda), y el cuidado lo estamos entendiendo como un venir abriendo lo sido (lo que ya siempre se era) y haciendo así presente, es decir, como tiempo. Y esto es lo que Heidegger llama temporalidad original, de la que derivaría el tiempo mundano o intramundano, el tiempo del reloj (\$\$ 61-66).

Pues bien, en la entrada en la tercera ronda analítica el cuidaclo se nos reveló como ser acerca de la muerte, y el venir la existencia a sí misma en ese su carácter, a asumirse en la posibilidad de no ser que ella ya siempre era, es el primer momento o éxtasis de lo que hemos llamado temporalidad original, y, por tanto, ésta tiene que ver esencialmente con el estar referida la existencia a su fin, es finitá. La temporalidad original es finita, y, si acaso, el problema es cómo puede surgir de la finitud de la apertura en que la existencia consiste la noción de un discurrir infinito del tiempo. Y si la temporalidad es finita, el hay, el haberlo, el Es y haber del mundo y del ente, del quedar abierto el mundo y descubierto el ente, que es como lo que la existencia se entiende en la segunda ronda, es finnitud. El horizonte de la comprensión del ser por la que se caracteriza la existencia es la temporalidad original y ésta es radical finitud. Así pues, el haber, el ser, en cuanto cae bajo la comprensión de la existencia, no es sino finitud.

\section{FinITUd E INFINITUD}

Pero precisamente cuando se llega a este punto, la argumentación de Heidegger deja de convencer. Y convence mucho menos la crítica que Heidegger hace de Hegel en el § 82, el parágrafo penúltimo de Ser y tiempo. Ya he dicho que esta tercera ronda analítica de Ser y tiempo depende mucho de conceptos del libro V de la Metafísica de Aristóteles: lo "perfecto", lo completo (téleion), y limite (peras), y también del concepto de "aquello por lo que o aquello por lo cual" (to hou heneka). Y he dicho también que incluso es en el análisis de esos conceptos aristotélicos cuando a Heidegger le amanece una noción que es esencial en esta tercera ronda, a saber: la del ser acerca de la muerte (Sein zum Tode). Pero llama la atención el que de este análisis esté completamente

26 Aprovechando que en alemán el participio pasado gewesen (sido) del verbo Sein (ser) tiene aspecto de infinitivo de un verbo, Heidegger forma el participio de presente (gewesende) correspondiente a ese infinitivo (en alemán el participio de presente del verbo lieben, amar, es liebender, amante, el que ama). Es como si en castellano, con el participio pasado (sido) del verbo ser formásemos un participio de presente y dijésemos "sidente" (gewesend) 
ausente cualquier referencia a la recepción y análisis que de esos mismos conceptos hace Hegel sobre todo en el libro primero de la Ciencia de la Lógica. Esos conceptos: teleion, peras, to hou heneka son también, como he dicho, los ingredientes de la noción de Hegel de "negatividad referida a sí misma". Pues lo que Heidegger llama temporalidad original no dista nada de lo que Hegel llama negatividad referida a sí misma, es decir, de lo que Hegel llama concepto o estructura de concepto: en lo otro no ser sino sí mismo, no ser sino estando referido a lo absolutamente otro de sí en que uno consiste.

Y en el punto de la Crítica de la razón pura en que se sitúa Hegel, esta idea de "en lo otro no ser sino sí mismo significa": en el consistir la razón kantiana en el no-ser de lo absolutamente otro de ella y estar en el lugar de ese absoluto que clla no es y en el haberse de tomar, por tanto, en consideración como pudiendo también no ser y estar así por encima de sí misma y de todo: es así como la razón especulativa es ella. Y así es también en Heidegger. Pero no ser sino siéndose lo absolutamente otro de sí, o simplemente lo completamente otro, ya último de sí, este no consistir últimamente sino en su no-ser, para Hegel no es finitud sino infinitud ${ }^{27}$.

Precisamente el concepto de finitud de la temporalidad original es el más chocante de Heidegger, porque es la misma articulación de finitud, limite e infinitud del libro primero de la Ciencia de la lógica, pero mal analizada en comparación con el análisis de Hegel o, por mejor decir, simplemente no ana-

27 A la relación entre el tiempo (considerado no desde el advenir finito, como quiere Heidegger, sino desde el ahora que supueslamente se re-crea a sí mismo y brola indefinidanente de sí mismo) y la eternidad, sc refiere Heidegger en varios lugares de su obra, por ejemplo, en su curso de 1929 Introducción a la Filosofía, remitiéndose a la idea proveniente de Platón del ahora como trasunto de lo eterno, a la que me he referido más arriba. Cfr. HEIDEGGER. Martin, Introducción a la Filosofía, traducción de Manuel Jiménez Redondo, Madrid: Tecnos, 1996. En múltiples pasajes de la Fenomenología del espíritu y sobre todo en el último capítulo del libro, Hegel ser refierc al ticmpo, considerado desde el ahora, como concepto intuido, como un quedar a la vista el concepto. Diríase, por tanto, que Hegel hace suyo el motivo platónico del ahora como trasunto del concepto, de lo infinito, de lo eterno. El ahora no es el ahora que él es sin dejar ya de serto y sin convertirse en el ahora que él aún no era, ecc., lo cual es el queclar ahí delante la negalividad del concepto, un continuo no consistir sino en el no-ser de sí mismo. Pues bien, si lo que Heidegger llama temporalidad original puede identificarse con la estructura de concepto de la que habla Hegel, resultaría que ambos están dicicndo lo mismo. El tiempo-ahora derivaría de la temporalidad original, como quiere Heidegger, es decir, de la estructura misma de concepto, tal como lo entiende Hegel. Además sobraría cl terminante deslinde de Heidegger frente a la tradición, deslinde que le hace incurrir en relación con la noción de tiempo en importantcs simplificaciones. La diferencia entre la temporalidad original y la estructura de concepto radica en que la relación finitud-infinitud, peras-apeiron, que, conforme a Hegel, cs escncial al concepto, Heidegger la dcja simplemente de lado. Acerca de las simplifacciones a las que me refiero, véase: ZUBIRI, Xavier ,El concepto descriptivo de tiempo" en: Realitas II: 1974-1975, Trabajos del Seminario Xavier Zubiri, Madrid, 1976, págs.. 7-47. 
lizada, sino sustituida por una apropiación bastante intuitiva de los conceptos dichos del libro $\mathrm{V}$ de la Metafísica de Aristóteles, muy determinada quizá por la voluntad de Kierkegaard de sustraer la representación religiosa a estos conceptos de Hegel, de poner la representación por encima del concepto, cosa que creo que no logra. Esos pasajes de Heidegger, más que análisis, son reproducción de ese pathos de Kierkegaard. El análisis de los ingredientes de ese pathos está más bien en Hegel. Los referentes tanto de Hegel como de Heidegger son casi los mismos, si no simplemente los mismos.

Y esto que digo no es remedio a ningún nihilismo, al nihilismo contemporáneo, que es nihilismo de lo absoluto, como muestra Beckett. Pero sí que pone el nihilismo en relación con las representaciones religiosas de la autokenosis de lo absoluto ${ }^{28}$, con el libérrimo darse de lo absoluto como negación en el arte, y con el carácter incondicionado que pretende para sí la libertad absoluta moderna. El concepto de lo absoluto es la hoguera del Sinaí, perenne, cuyo tenerse ella ante sí misma es un quedar quemado en ella todo, en la que nada se ve, de modo que la libertad no tiene más remedio que buscarse constantemente representaciones de ese su carácter absoluto, pero que ella sabe que sucumbirán a esa quema, a la quema definitiva que ella misma es como no-ser del absoluto que es el Absoluto. La mejor descripción de ello está en el libro segundo de la Ciencia de la lógica de Hegel, en la Lógica de la esencia.

Hegel podría, por tanto, muy bien decir que la existencia se caracteriza por una comprensión del ser. Y podría también decir que lo abierto que esta comprensión del ser implica, lo hemos estado entendiendo ya siempre en su estructura de concepto (en su estructura de lo que Heidegger llama temporclidad original). Y, por tanto, puede decir que el horizonte de toda comprensión posible del ser es el concepto, como infinitud precisamente, en el sentido que tan bien entendido quedaba para Hegel en el modo en que en los conceptos matemáticos del cálculo diferencial se entendían la infinitud y la finitud. Con lo que me parece, y esto es lo que yo quería decir, que el planteamiento de Heidegger (el horizonte de toda posible comprensión del ser es el tiempo), paradigmático de un rasgo del pensamiento contemporáneo que se entiende como un pensamiento que nada tiene que ver ya, que deja detrás el pensamiento de lo absoluto, se revela como rezumándose en pensamiento de lo absoluto, como no siendo sino repetición del pensamiento de lo absoluto, del pensamiento de Hegel.

28 Por así decirlo, en muchas ocasiones ello ya ocurre de por sí, internamente, como es el caso de algunas interpretaciones místicas de esas representaciones (véase, por ejemplo, el libro de San Juan de la Cruz, Subida al Monte Carmelo). También ello ocurre de por sí (y, por cierto, de forma muy próxima a la conceptuación de Hegel) en el contexto de la "teología dialéctica" de Karl Barth, de Rudolf Bultmann o del discutido Friedrich Gogarten. Véase, por ejemplo, el libro de este último: GOGARTEN, Friedich, Die Frage nach Gott, eine Vorlesung, Tübingen: J. C. B. Mohr (Paul Siebeck), 1968. 
Y otro tanto nos resultaría, si considerásemos la referencia a Hegel, cada vez más persistente, que se está produciendo desde otro rasgo del pensamiento contcmporáneo, el giro lingüístico, que parece estrechamente ligado al rasgo de pensamiento posmetafísico, es decir, si considerásemos el pensamiento de Hegel desde la hermenéutica filosófica, desde el giro semiótico que Derrida efectúa en la filosofía trascendental contemporánea y desde la recepción que de la obra de Hegel está teniendo lugar en el contexto de la filosofía analítica por parte de R. Brandom, J. McDowell y otros, que se quiere un Hegel sin metafísica de Hegel, un Hegel agarrado quizá como perspectiva última al concepto de reconocimiento del capítulo IV de la Fenomenología del espíritu. Pero para Hegel la exposición de ese concepto sólo se acaba en el capítulo VIII y, por tanto, ese concepto no puede ser lo que es sin la incondicionalidad que lo Absoluto le presta. Una recensión alemana, hecha quizá, según me parece, con cierto vago tono de descalificación, que no comparto, publicada en el periódico Frankfurter Allgemeine Zeitung (de 8 de diciembre de 2008), que se refería a un colectivo sobre la Fenomenología del espiritu de Hegel, en el que predominan las colaboraciones sobre el concepto de reconocimiento del cap. IV de la $\mathrm{Fe}$ nomenologia del espíritu ${ }^{29}$, llevaba por título: "Anerkennung, da lacht Hegel" (Reconocimiento, y Hegel se ríe de eso), lo cual en cierto modo tiene también algo de verdad, por lo menos en el sentido de que a veces el comentarista de Hegel o quien recurre a conceptos de Hegel remitiéndose a la autoridad de éste da por supuesta mucha más metafísica de Hegel de la que cree. Me parece que eso es claro en algunos trabajos de R. Brandom. ${ }^{30}$

29 VIEWEG, Klaus y WELSCH, Wolfgang (cds.), Hegels Phänomenologie des Geistes, Frank furt: Suhrkamp, 2008. Recensión: „Ancrkcnnung - da lacht Hegel“ (Frankfurter Allgemeine Zcitung, 8 de diciembre de 2008, nr. 287 , pág. 37).

30. Es, según me parece, lo que ocurre sobrc todo cn la última de las tres conferencias dc Robert Brandom "Animating Icleas of Idcalism" (The 2007 Woodbridge Lectures. 12-14 November, 2007, Columbia University). En las dos primeras confereneias Brandom recurre al modelo kantiano de la autonomía para dar razón de los conceptos nomativos o dcontológicos implicados en lo que Frege Ilama force. En la terccra conferencia, titulada „History,. Reason, and Reality", a fin de dar razón de la independencia relativa del normative content respecto a la normative force, Brandom amplía el modelo kantiano de la autonomía para convertirlo en el modelo hegcliano del reconocimiento, que es cntendido por Brandom como un desarrollo consecuente (y sustancial) del primero, algo así como una Aufhebung hegeliana y pragmatista del planteamiento kantiano. Brandom da por supuesto o introduce, stapuestamente de forma ajena a la metafísica de lo absoluto de Hegel, un concepto de reconocimiento, que creo que depende por entero de csa metafísica. O al menos, así lo entiendc expresamente Hegel al final del cap. VI, del cap. VII y en cl cap. VIlI de la Fenomenologia del espiritu. Hegel sólo da por obtenido ese concepto en el cap. VIII del libro, no en el cap. IV. Ello, desde lucgo, no resta ningún interés a la brillante reformulación que en términos kantianos y hegelianos Brandom hace de las nociones de Frege force, sense y reference. 